\title{
Association Between Anaemia And Low Birth Weight Among HIV -Infected Pregnant Women Aged 15 - 49 Years In Zimbabwe : A Cross-Sectional Study
}

Dorothy T Chisare ( $\nabla$ dorothyct9@gmail.com )

University of the Witwatersrand School of Public Health https://orcid.org/0000-0001-8194-7674

\section{Simbarashe Takuva}

University of the Witwatersrand Faculty of Health Sciences

Tariro J. Basera

Medecins Sans Frontieres

Natasha Khamisa

IIE MSA

Jacqueline Witthuhn

IIE MSA

\section{Research}

Keywords: Low birth weight, anaemia, HIV infected pregnant women, Zimbabwe

Posted Date: February 27th, 2020

DOI: https://doi.org/10.21203/rs.2.24714/v1

License: (c) (i) This work is licensed under a Creative Commons Attribution 4.0 International License. Read Full License 


\section{Abstract}

\section{Background}

In Zimbabwe, almost 25\% of infants are born with low birth weight (LBW). LBW accounts for over half of the neonatal deaths in the country. Anaemia during pregnancy has been inconsistently associated with an increased risk of LBW. However, very little data is available from countries where HIV prevalence is high, wherein HIV is also known to be a common risk factor to LBW. This study examined the relationship between maternal anaemia and LBW among HIVinfected pregnant women in Zimbabwe.

\section{Methods}

This was a secondary data analysis of the 2015 Zimbabwe Demography and Health Survey. Data for 809 HIV positive women aged 15-49 years and their infants from all live births preceding the survey by 5 years were included in the study. Modified-Poisson regression methods were used to determine the association between anaemia and LBW while adjusting for other risk factors.

\section{Results}

The prevalence of maternal anaemia and LBW among the HIV-infected pregnant women was $42.3 \%(n=342)$ and $16.3 \%(n$ $=132)$ respectively. The prevalence of LBW was $14.6 \%(n=50)$ and $17.6 \%(n=82)$ among anaemic and non-anaemic HIV positive women respectively $(p=0.264)$. HIV infected pregnant women with anaemia had a $25 \%$ less chance of giving birth to infants with LBW compared to HIV infected mothers without anaemia, however, the association was not statistically significant (RR 0.75; 95\% Cl 0.53-1.05).

\section{Conclusions}

The findings demonstrate a high prevalence of anaemia and LBW among HIV infected pregnant women. Nonetheless, maternal anaemia was not associated with LBW. There is a need for adapted monitoring of HIV-positive pregnant women and affordable improved nutrition during antenatal care to reduce the risk of LBW infants and maternal anaemia levels. Further research examining the relationship between maternal anaemia and LBW among HIV positive pregnant women whilst factoring in the role of ART and the severity of anaemia is required.

\section{Background}

Birth weight is a significant indicator of the immediate and future health status of a newborn and predicts the child's chances of survival [1]. As defined by the World Health Organization (WHO), infants with a birth weight less than 2500grams (2.5kilograms) are known as low birth weight (LBW) infants regardless of gestational age [2]. Globally, more than 20 million infants, accounting for 15.5\% of all births are born with a LBW [3], the most prevalent regions being South Asia (30\%), followed by Sub-Saharan Africa (SSA) (18\%) and South America (17.9\%)[4, 5]. LBW is a leading underlying factor of neonatal mortality, accounting for $38 \%$ of all infant deaths in $2000,45 \%$ in 2015 and $60-80 \%$ (30 million deaths) in $2017[4,6]$. With a prevalence of 10-24\% varying by region and accounting for over half of neonatal deaths in Zimbabwe in 2015, LBW is a prudent maternal and child health issue in the country [7, 3]. He and colleagues indicate that LBW infants are 40 times more likely to die within the first 30 days of life compared to normal birth weight babies (NBW) [6].

Maternal anaemia is a significant global health issue that affects about 500 million women of reproductive age [8]. Anaemia during pregnancy increases the risk of LBW and this risk is exacerbated by inadequate access to prenatal care, socio-economic status of the pregnant woman, and exposure to infectious diseases such as sexually transmitted 
diseases, malaria or HIV infection [5]. Studies have shown that infants born to HIV positive mothers have a 9.87 times higher risk of LBW compared to HIV unexposed infants [6], and those that survive become ill within the first six days of life [9].Moreover, high rates of anaemia, a risk factor to LBW have been reported among HIV positive pregnant women ranging from 73\% in South Africa, 40\% in Kenya, 56.4\% in Tanzania and 37.7\% in Zimbabwe from 2011 to 2013 [10].LBW infants born to anaemic mothers have a two-fold likelihood of neonatal mortality than those born to non-anaemic women [11]. The consequences of LBW on the health of infants include cognitive and neurological impairment, cholesterol, obstructive lung disease, renal damage, impaired immune function and chronic conditions such as high blood pressure and diabetes in their adulthood years [12].A threshold of $>5.0 \%$ prevalence of anaemia is deemed a public health concern whilst $>40 \%$ prevalence a severe health issue and could be fatal to both woman and child or cause complications such as LBW [2]. Studies have reported high prevalence of LBW among anaemic pregnant women ranging from $30 \%$ in Tanzania [11] to $53.6 \%$ in Zimbabwe [3].

There is a dearth in literature to highlight the association between anaemia and LBW in the context of HIV or the mechanisms through which both diseases simultaneously contribute to LBW in Zimbabwe. Such a dearth in knowledge affects the methods of the Zimbabwean health care delivery system on optimally responding to the needs of HIV exposed infants [9]. Given the high prevalence and public health importance of HIV infection, anaemia in pregnancy and LBW as a major risk factor for infant mortality in Zimbabwe, this study assessed whether maternal anaemia was associated with LBW in the context of HIV infection. Identifying the association of both conditions on LBW is crucial in improving the developmental outcomes of HIV exposed infants who are at increased risk of LBW compared to non-exposed infants [13] and support the development of effective strategies targeting LBW within neonatal health programs in Zimbabwe. The objective of this study was to determine the prevalence of LBW and its association with maternal anaemia among HIV infected pregnant women aged 15 to 49 years in Zimbabwe.

\section{Materials And Methods}

Study Design

The primary study, the 2015 Zimbabwe Demographic and Health Survey 2015 (ZDHS)was a cross sectional survey where data on the outcome (LBW) and other explanatory variables such as anaemia was collected at a single point in time hence this study used a cross-sectional design to analyse the secondary data.

Study Setting, Population, And Sampling

Zimbabwe is in the southern region of Africa and is bordered by four countries namely Botswana, Zambia, South Africa, Mozambique to the north east [14]. Based on Zimstat (2016) estimates, Zimbabwe has a population of approximately 14.5 million people, and the average life expectancy is 58 years. Between 1990 and 2015, the infant mortality rate averaged 50 deaths per 1000 live births [14] ;and the under-five mortality was 76 deaths per 1000 live births [14].

The ZDHS is a national- level household-based survey undertaken in all of Zimbabwe's ten provinces, with the last survey conducted in 2015. No sampling was done in this study as it involved a secondary analysis of survey data, therefore all HIV positive women who reported on the birth weight of their infant, with an anaemia test result meeting the inclusion criteria, constituted the analysis sample. In total, 809 HIV positive women aged 15-49 years met the inclusion criteria. Nonetheless, a test was performed to assess the adequacy of the sample for this study using the following power test calculation:

\section{$\mathrm{N}=(z \alpha / E)^{2} P(1-P)$}


where $\mathrm{N}$ is the estimated minimum sample size, $\mathrm{P}$ is the expected proportion of LBW (15\%), za is the confidence level of $95 \%$ (standard value is 1.96) and $\mathrm{E}$ is the margin of error (+-5\%) therefore;

$$
\begin{aligned}
\mathrm{N}= & \left(\frac{1.96}{0.05}\right)^{2} \times 0.15(1-0.15) \\
= & \underline{280}
\end{aligned}
$$

Therefore, the sample size of 809 is adequate to detect any differences with $5 \%$ margin of error.

The ZDHS used a stratified, two-stage cluster sampling approach from July to December 2015.The first stage involved selecting samples from a master sampling frame constructed from enumeration (400 enumeration areas (EAs) that comprised 166 EAs in urban areas and 234 in rural areas) and the second stage involved systematic sampling of the households listed from each cluster ensuring adequate numbers of completed interviews. Those who lived in institutional groups such as army barracks, clinics or hospitals, police stations, and boarding schools were excluded from the ZDHS. Trained personnel within the ZDHS interviewed a final sample of 9955 women aged 15-49 years who were either permanent residents or overnight visitors of the included households following their consent using computer assisted personal interviewing (CAPI) in the three local languages. Of the 9955 women, there were 20791 live births recorded and each respondent (mother) was asked to provide a detailed birth history for births in the preceding five years before survey. The questionnaires were adapted from model survey instruments developed for the DHS Program. Birth weight was recorded using the metric scale (in grams)[14]. HIV and anaemia testing was performed on those participants who consented to testing [14].

Variable Definitions

The study outcome LBW was a dichotomous variable, low birth weight = "Yes" if $<2500 \mathrm{~g}$ or "No" if $>2500 \mathrm{~g}$. Anaemia was categorized as anaemia $(\leq 12.0 \mathrm{Hb} \mathrm{g} / \mathrm{dl})$ and no anaemia $(>12.0 \mathrm{Hb} \mathrm{g} / \mathrm{dl})$.

Data Analysis

The ZDHS data was provided in STATA file format and it was imported to STATA version 13 (Stata Corp, College Station, Texas, USA). Data cleaning processes, coding and analysis was done in STATA version 13 (Stata Corp, College Station, Texas, USA). Missing values and duplicates were dropped. The distribution the socio-demographic, socio-economic and obstetric characteristics of the study participants as well as the prevalence of LBW are expressed as frequencies with their corresponding percentages. In addition, the mean and standard deviation of Low birth weight is presented as it was normally distributed. The Pearson Chi-square test was used to test differences between explanatory variables and LBW.

Multivariable Poisson regression models with robust error variance were used adjusting for clustering to examine the association between anaemia and low birth weight adjusting for other confounding variables. LBW had a common prevalence $(\geq 10 \%)[15]$ hence the modified Poisson regression approach was used to explore predictors of low birth weight with; maternal anaemia, maternal age, maternal education status, maternal employment, wealth quintile, residence type LBW, maternal BMI, iron and folate supplement intake and number of ANC visits in our study participants. Poisson regression avoids the bias of overestimating the prevalence of the outcome in question, hence presenting more robust findings compared to using logistic regression [15]. Crude and adjusted relative risks (RR) with corresponding 95\% confidence intervals $(\mathrm{Cl})$ are reported. Variables that were a priori, had a $\mathrm{p}$-value $<0.20$ on bivariate analysis were considered as potential candidates for inclusion into the multivariable models. All p-values $<0.05$ were considered statistically significant.

Results

Page $4 / 18$ 
Figure 1 illustrates selection process of participants also highlighting reasons for the excluded participants.

The socio-demographic, socio-economic and obstetric factors are illustrated in Table 1. Overall, 809 HIV-positive women were included in the study. As illustrated in Table 1, most of the HIV-positive women were between the ages of 2534 years $(53.8 \%, n=435)$ followed by the 35 year and above age group $(25.3 \%, n=205)$ and lastly $20.9 \%$ were $15-$ 24 years $(n=169)$. Among women with anaemia, most of them were $25-34$ years of age $(54.1 \%, n=185)$ while $26.6 \%(n$ $=91$ ) were aged 35 years and above. Most of the married women did not have anaemia $(77.3 \%, n=361)$. About $53.8 \%$ of female children $(n=435)$ and $46.2 \%$ male children $(n=374)$ were born to anaemic women. The mean (standard deviation [SD]) birth weight of live births was 3124.8 grams ( \pm 622.9$)$. Infants born to anaemic mothers were on average 73.8 grams heavier than those born to non-anaemic mothers. When the birth weight was dichotomized, the prevalence of LBW among infants born to anaemic women was lower $(14.6 \%, n=50)$ than their counterparts $(17.6 \%, n=82)$, nonetheless the differences were not statistically significant $(p=0.264)$.

Approximately half of the infants were second or third born children with no major differences between anaemic women $(50.3 \%, n=172)$ and non-anaemic women $(49.5 \%, n=231)$. Overall, $99.3 \%(806)$ of mothers received at least primary education, of which most of the mothers with anaemia $(67 \%, n=229,67 \%)$ and without anaemia $(68.3 \%, n=319)$, had tertiary education. Sixty percent of women in the study were employed $(n=485)$, with a lower percentage of employed mothers amongst those with anaemia (56.4\%). Most women resided in rural communities $(60 \%, n=485)$ with marginal differences between women who had anaemia and those without anaemia ( $60.5 \%$ and $59.5 \%$ respectively). Approximately, a third of the participants were from a household in the fourth wealth quintile $(31.8 \%, \mathrm{n}=$ 257).Approximately, $88.3 \%(n=576)$ of the study participants took iron supplements during their last pregnancy and a higher percentage of these women were anaemic $(90.8 \%, n=247)$. Fewer women took folate supplements during their last pregnancy $(50.6 \%, \mathrm{n}=330)$ and this was similar among anaemic women and non-anaemic women $(50.4 \%$ and $50.8 \%$ respectively). Most women had normal BMI $(63.1 \%, n=510)$, most of whom were non-anaemic $(64.2 \%, n=299)$. Approximately half $(51.4 \%, n=335)$ of the study participants had the recommended 5 or more ANC visits during pregnancy and there were no differences in ANC attendance between non-anaemic $(50.5 \%, n=192)$ and anaemic women $(52.6 \%, n=143)($ Table 1$)$. 
Table 1

Socio-demographic, socio-economic and obstetric characteristics of the study participants

\begin{tabular}{|c|c|c|c|}
\hline Variables & Total & Anaemia & No anaemia \\
\hline & $\mathrm{N}(\%)$ & Mean (STD) & Mean (STD) \\
\hline \multirow[t]{2}{*}{ Low Birth Weight(g) } & $3124.8(622.9)$ & $3166.3(648.3)$ & 3049.5 (602.6) \\
\hline & $\begin{array}{l}\text { Total } \\
\text { N (\%) }\end{array}$ & $\begin{array}{l}\text { Anaemia } \\
\mathrm{n}(\%)\end{array}$ & $\begin{array}{l}\text { No anaemia } \\
\mathrm{n}(\%)\end{array}$ \\
\hline $\begin{array}{l}\text { Low Birth Weight(g) } \\
\text { Yes }(\leq 2500 \mathrm{~g}) \\
\text { No (above } 2500 \mathrm{~g} \text { ) }\end{array}$ & $\begin{array}{l}132(16.3) \\
677(83.7)\end{array}$ & $\begin{array}{l}50(14.6) \\
292(85.4)\end{array}$ & $\begin{array}{l}82(17.6) \\
385(82.4)\end{array}$ \\
\hline $\begin{array}{l}\text { Maternal Age } \\
15-24 \\
25-34 \\
\geq 35\end{array}$ & $\begin{array}{l}169(20.9) \\
435(53.8) \\
205(25.3)\end{array}$ & $\begin{array}{l}66(19.3) \\
185(54.1) \\
91(26.6)\end{array}$ & $\begin{array}{l}103(22.1) \\
250(53.5) \\
114(24.4)\end{array}$ \\
\hline $\begin{array}{l}\text { Sex of Child } \\
\text { Male } \\
\text { Female }\end{array}$ & $\begin{array}{l}374(46.2) \\
435(53.8)\end{array}$ & $\begin{array}{l}156(45.6) \\
186(54.4)\end{array}$ & $\begin{array}{l}218(46.7) \\
249(53.3)\end{array}$ \\
\hline $\begin{array}{l}\text { Parity } \\
1 \text { st Child } \\
2-3 \\
\geq 4\end{array}$ & $\begin{array}{l}109(13.5) \\
403(49.8) \\
297(36.7)\end{array}$ & $\begin{array}{l}50(14.6) \\
172(50.3) \\
120(35.1)\end{array}$ & $\begin{array}{l}59(12.6) \\
231(49.5) \\
177(37.9)\end{array}$ \\
\hline $\begin{array}{l}\text { Marital status } \\
\text { Never married } \\
\text { Married/ living together } \\
\text { Divorced/separated/widowed }\end{array}$ & $\begin{array}{l}54(6.7) \\
592(73.2) \\
163(20.2)\end{array}$ & $\begin{array}{l}33(9.7) \\
231(67.5) \\
78(22.8)\end{array}$ & $\begin{array}{l}21(4.5) \\
361(77.3) \\
85(18.2)\end{array}$ \\
\hline $\begin{array}{l}\text { Maternal Education status } \\
\text { None } \\
\text { Primary } \\
\text { Secondary } \\
\text { Tertiary }\end{array}$ & $\begin{array}{l}6(0.7) \\
98(12.1) \\
157(19.4) \\
548(67.7)\end{array}$ & $\begin{array}{l}6(1.8) \\
45(13.2) \\
62(18.1) \\
229(67.0)\end{array}$ & $\begin{array}{l}0(0.0) \\
53(11.4) \\
95(20.3) \\
319(68.3)\end{array}$ \\
\hline $\begin{array}{l}\text { Maternal Employment } \\
\text { Employed } \\
\text { Non-employed }\end{array}$ & $\begin{array}{l}485(60.0) \\
324(40.1)\end{array}$ & $\begin{array}{l}193(56.4) \\
149(43.6)\end{array}$ & $\begin{array}{l}292(62.5) \\
175(37.5)\end{array}$ \\
\hline $\begin{array}{l}\text { Wealth Quintile } \\
\text { Lowest } \\
\text { Second } \\
\text { Middle } \\
\text { Fourth } \\
\text { Highest }\end{array}$ & $\begin{array}{l}162(20.0) \\
121(15.0) \\
141(17.4) \\
257(31.8) \\
128(15.8)\end{array}$ & $\begin{array}{l}71(20.8) \\
49(14.3) \\
59(17.3) \\
107(31.3) \\
56(16.4)\end{array}$ & $\begin{array}{l}91(19.5) \\
72(15.4) \\
82(17.6) \\
150(32.1) \\
72(15.4)\end{array}$ \\
\hline $\begin{array}{l}\text { Residence Type } \\
\text { Urban } \\
\text { Rural }\end{array}$ & $\begin{array}{l}324(40.1) \\
485(60.0)\end{array}$ & $\begin{array}{l}135(39.5) \\
207(60.5)\end{array}$ & $\begin{array}{l}189(40.5) \\
278(59.5)\end{array}$ \\
\hline $\begin{array}{l}\text { Maternal BMI } \\
\text { Low (BMI<18.5) } \\
\text { Normal }(\mathrm{BMI} 18.5-24.9) \\
\text { Overweight/obese }(\mathrm{BMI} \geq 25)\end{array}$ & $\begin{array}{l}65(8.1) \\
510(63.1) \\
233(28.8)\end{array}$ & $\begin{array}{l}37(10.8) \\
211(61.7) \\
94(27.5)\end{array}$ & $\begin{array}{l}28(6.0) \\
299(64.2) \\
139(29.8)\end{array}$ \\
\hline $\begin{array}{l}\text { Took Iron Supplements } \\
\text { Yes } \\
\text { No }\end{array}$ & $\begin{array}{l}576(88.3) \\
76(11.7)\end{array}$ & $\begin{array}{l}247(90.8) \\
25(9.2)\end{array}$ & $\begin{array}{l}329(86.6) \\
51(13.4)\end{array}$ \\
\hline
\end{tabular}




\begin{tabular}{|llll|}
\hline Variables & Total & Anaemia & No anaemia \\
\hline $\begin{array}{l}\text { Took Folate Supplements } \\
\text { Yes }\end{array}$ & $330(50.6)$ & $137(50.4)$ & $193(50.8)$ \\
No & $322(49.4)$ & $135(49.6)$ & $187(49.2)$ \\
\hline No. of ANC visits & & & \\
Inadequate $(<5)$ & $317(48.6)$ & $129(47.4)$ & $188(49.5)$ \\
Adequate $(\geq 5)$ & $335(51.4)$ & $143(52.6)$ & $192(50.5)$ \\
\hline
\end{tabular}

Prevalence of maternal anaemia and LBW among HIV pregnant women in Zimbabwe, 2015

As illustrated in Fig. 4, the prevalence of maternal anaemia among HIV positive pregnant women in Zimbabwe was $42.3 \%$ while the overall prevalence of low birth weight in Zimbabwe in 2015 was $16.3 \%$ (Fig. 5). This was higher in women that had no anaemia (17.6\%) compared to those with anaemia (14.6\%), nonetheless the differences were not statistically significant $(p=0.264)$.

Factors associated with LBW

In bivariate analysis, LBW among mothers was predicted by sex of child, marital status, wealth quintile, residence type and maternal BMI status ( $p<0.05$ ). In the adjusted (multivariable) model, maternal BMI, sex of child and parity were significantly associated with LBW.

The risk of LBW decreased with an increase in maternal BMl; with lower risk among women with higher BMI i.e. overweight/obese (RR $0.41 ; 95 \% \mathrm{Cl} 0.22-0.74)$ and those who were of a normal weight (RR $0.71 ; 95 \% \mathrm{Cl} 0.45-1.12$ ) compared to underweight women. Female infants had a higher risk of LBW compared with male infants (RR $1.64 ; 95 \% \mathrm{Cl}$ 1.13-2.40). Additionally, the risk of LBW decreased with increasing parity, whereby the second or third born infant have a $38 \%$ less likelihood of LBW, while fourth or above had $50 \%$ less risk of LBW. Moreover, the risk of LBW decreased with frequent ANC visits (17\% lower risk for those with 5 or more ANC visits) (RR 0.78; 95\% Cl 0.55-1.09). Maternal anaemia, maternal occupation, wealth quintile, residence type, maternal education, iron supplement intake, folate supplement intake and marital status were not statistically significant in the multivariable model. However, women with anaemia had a $25 \%$ less likelihood to give birth to babies with LBW (RR 0.75; 95\% Cl 0.53-1.05) compared with mothers without anaemia. Also the more the ANC visits, the less likelihood of LBW infants i.e. adequate visits(>5) (RR 0.78; 95\% Cl 0.551.09).There is also a decreased risk of LBW among 25-34 year aged mothers and those 35 and above (22\% and $7 \%$ respectively) compared to those of the younger age group, 15-24 years. 
Table 2

Risk factors for LBW among HIV infected pregnant women in Zimbabwe, 2015

\begin{tabular}{|c|c|c|c|c|}
\hline Variables & Unadjusted RR (95\% Cl) & p-value & Adjusted RR (95\% Cl) & p-value \\
\hline $\begin{array}{l}\text { Maternal Anaemia }(\mathrm{Hb}, \mathrm{g} / \mathrm{dl}) \\
\text { Non-anemic }(>12.0) \\
\text { Anemic }(\leq 12.0)\end{array}$ & $\begin{array}{l}\text { Ref } \\
0.83(0.59-1.18)\end{array}$ & 0.304 & $\begin{array}{l}\text { Ref } \\
0.75(0.53-1.05)\end{array}$ & 0.097 \\
\hline $\begin{array}{l}\text { Maternal Age } \\
15-24 \\
25-34 \\
\geq 35\end{array}$ & $\begin{array}{l}\text { Ref } \\
0.78(0.53-1.14) \\
0.93(0.59-1.46)\end{array}$ & $\begin{array}{l}0.194 \\
0.747\end{array}$ & $\begin{array}{l}\text { Ref } \\
1.27(0.80-2.04) \\
1.87(0.96-3.65)\end{array}$ & $\begin{array}{l}0.312 \\
0.067\end{array}$ \\
\hline $\begin{array}{l}\text { Sex of Child } \\
\text { Male } \\
\text { Female }\end{array}$ & $\begin{array}{l}\text { Ref } \\
1.60(1.14-2.27)\end{array}$ & $0.007 *$ & $\begin{array}{l}\text { Ref } \\
1.64(1.13-2.40)\end{array}$ & $0.010 *$ \\
\hline $\begin{array}{l}\text { Parity } \\
1 \text { st Child } \\
2-3 \\
\geq 4\end{array}$ & $\begin{array}{l}\text { Ref } \\
0.67(0.45-1.01) \\
0.66(0.43-1.02)\end{array}$ & $\begin{array}{l}0.054 \\
0.060\end{array}$ & $\begin{array}{l}\text { Ref } \\
0.62(0.39-1.00) \\
0.50(0.26-0.95)\end{array}$ & $\begin{array}{l}0.051 \\
0.034^{\star}\end{array}$ \\
\hline $\begin{array}{l}\text { Marital status } \\
\text { Never married } \\
\text { Married/living together } \\
\text { Divorced/separated/widowed }\end{array}$ & $\begin{array}{l}\text { Ref } \\
0.63(0.41-.97) \\
0.50(0.27-0.92)\end{array}$ & $\begin{array}{l}0.035^{\star} \\
0.026^{\star}\end{array}$ & $\begin{array}{l}\text { Ref } \\
0.80(0.47-1.35) \\
0.61(0.30-1.22)\end{array}$ & $\begin{array}{l}0.399 \\
0.160\end{array}$ \\
\hline $\begin{array}{l}\text { Maternal Education status } \\
\text { None } \\
\text { Primary } \\
\text { Secondary } \\
\text { Tertiary }\end{array}$ & $\begin{array}{l}\text { Ref } \\
0.73(0.22-2.43) \\
0.50(0.15-1.67) \\
0.44(0.14-1.39)\end{array}$ & $\begin{array}{l}0.614 \\
0.259 \\
0.160\end{array}$ & $\begin{array}{l}\text { Ref } \\
0.49(0.16-1.92) \\
0.30(0.08-1.18) \\
0.30(0.08-1.05)\end{array}$ & $\begin{array}{l}0.283 \\
0.085 \\
0.060\end{array}$ \\
\hline $\begin{array}{l}\text { Maternal Employment } \\
\text { Non-employed } \\
\text { Employed }\end{array}$ & $\begin{array}{l}\text { Ref } \\
0.91(0.66-1.27)\end{array}$ & 0.585 & $\begin{array}{l}\text { Ref } \\
1.02(0.71-1.46)\end{array}$ & 0.927 \\
\hline $\begin{array}{l}\text { Wealth Quintile } \\
\text { Lowest } \\
\text { Second } \\
\text { Middle } \\
\text { Fourth } \\
\text { Highest }\end{array}$ & $\begin{array}{l}\text { Ref } \\
1.09(0.66-1.78) \\
0.93(0.55-1.58) \\
0.69(0.43-1.10) \\
0.51(0.28-0.93)\end{array}$ & $\begin{array}{l}0.738 \\
0.799 \\
0.120 \\
0.029 \star\end{array}$ & $\begin{array}{l}\text { Ref } \\
1.54(0.90-2.63) \\
1.20(0.68-2.13) \\
0.83(0.38-1.79) \\
0.53(0.20-1.42)\end{array}$ & $\begin{array}{l}0.120 \\
0.531 \\
0.602 \\
0.202\end{array}$ \\
\hline $\begin{array}{l}\text { Residence Type } \\
\text { Urban } \\
\text { Rural }\end{array}$ & $\begin{array}{l}\text { Ref } \\
1.48(1.06-2.07)\end{array}$ & $0.022^{*}$ & $\begin{array}{l}\text { Ref } \\
0.73(0.36-1.48)\end{array}$ & 0.399 \\
\hline $\begin{array}{l}\text { Maternal BMI } \\
\text { Low (BMI<18.5) } \\
\text { Normal (BMI 18.5-24.9) } \\
\text { Overweight/obese }(\mathrm{BMI} \geq 25)\end{array}$ & $\begin{array}{l}\text { Ref } \\
0.67(0.43-1.04) \\
0.43(0.25-0.73)\end{array}$ & $\begin{array}{l}0.072 \\
0.002^{\star}\end{array}$ & $\begin{array}{l}\text { Ref } \\
0.71(0.45-1.12) \\
0.41(0.22-0.74)\end{array}$ & $\begin{array}{l}0.144 \\
0.003^{\star}\end{array}$ \\
\hline $\begin{array}{l}\text { Took Iron Supplements } \\
\text { No } \\
\text { Yes }\end{array}$ & $\begin{array}{l}\text { Ref } \\
0.68(0.44-1.06)\end{array}$ & 0.088 & $\begin{array}{l}\text { Ref } \\
0.73(0.46-1.15)\end{array}$ & 0.177 \\
\hline $\begin{array}{l}\text { Took Folate Supplements } \\
\text { No } \\
\text { Yes }\end{array}$ & $\begin{array}{l}\text { Ref } \\
0.77(0.55-1.09)\end{array}$ & 0.141 & $\begin{array}{l}\text { Ref } \\
0.79(0.55-1.13)\end{array}$ & 0.190 \\
\hline $\begin{array}{l}\text { No. of ANC visits } \\
\text { Inadequate }(<5) \\
\text { Adequate }(\geq 5)\end{array}$ & $\begin{array}{l}\text { Ref } \\
0.78(0.55-1.09)\end{array}$ & 0.146 & $\begin{array}{l}\text { Ref } \\
0.83(0.60-1.15)\end{array}$ & 0.265 \\
\hline
\end{tabular}




\section{Discussion}

This study investigated the association between maternal anaemia and LBW among HIV infected pregnant women aged 15-49 years in Zimbabwe. The results demonstrated that maternal anaemia was not associated with LBW. Women with anaemia had lower risk of LBW compared to non-anaemic women. Maternal BMI status, sex of child and parity were found to be significant risk factors of LBW among infants of HIV infected women in the multivariable analysis. Women with normal weight and those obese or overweight had lower risk of having LBW infants compared to underweight women (low BMI of < 18.5). It was found that female infants had a higher risk of LBW as opposed to male infants and that as parity increased, the risk of LBW decreased.

The prevalence of anaemia in this cross-sectional study was $42.3 \%$ amongst HIV infected women, while the prevalence of LBW among anaemic women was $14.6 \%$. Other studies have reported prevalence of maternal anaemia amongst HIV positive women in developing countries ranging between $14-62 \%[10,16,4]$. The overall LBW prevalence in Zimbabwe in this study population of HIV positive infected women in 2015 was $16.3 \%$. The LBW prevalence reported in this study is higher compared to $15 \%$ reported for the SSA region, $9 \%$ in Malawi [3], and a prevalence of $9.5 \%$ among the general population of women of reproductive age in Zimbabwe as reported in the 2010-2011 Demographic and Health Survey report [14]. These results demonstrate an increase in prevalence from 2011 to 2015. The increase in LBW prevalence in the Zimbabwean setting as explained by Feresu, Harlow \& Woelk is possibly due to limited data and a lack of understanding of the predictors associated with LBW, especially the role of HIV which still needs to be characterized in the context of LBW patterns [3].This increasing trend is particularly concerning given the impact of LBW on the developmental outcomes of the infants. LBW increases the risk of learning difficulties, cerebral palsy, visual and auditory deficits among infants [18].

\section{Obstetric Factors}

Maternal anaemia was not associated with LBW in this study. Similarly, Kader and Perera also reported no association between LBW and maternal anaemia [18]. A meta-analysis of studies investigating prevalence, risk factors and LBW among anaemic women living with HIV also reported no association between maternal anaemia and LBW[4].They explained that a physiological decrease in haemoglobin levels during late pregnancy maybe due to normal red cells and plasma volume expansions and does not necessarily imply that one is anaemic which may explain the lack of association. Studies have reported conflicting findings. On the other hand, some studies have found that pregnant women with high plasma volumes have given birth to infants with a higher birth weight than average [4]. In contrast, Fowkes and colleagues reported an inverse association between birth weight and haemoglobin levels during late stages of pregnancy whereby birthweight of infants was significantly larger among anaemic women in comparison with non-anaemic women [19].Contrary to these findings, Kader \& Perera and Rahmati found an association between anaemia and LBW, however only within the first trimester of the pregnancy not the second and third trimesters, while Haider found an association only in the first trimester $[18,4,21]$. From this standpoint, it is speculated that the severity of anaemia within the three gestation periods of pregnancy should be considered. However, this study did not stratify anaemia in the analysis by gestation period (first, second and third trimester) due to the small proportion of women with anaemia within the sample which would result in extremely wide confidence intervals and lower precision of the findings.

The present study also confirmed the findings about the relationship between maternal BMI and LBW which was statistically significant. Women with poor nutritional status, reflected in low BMI $(<18.5)$ had a higher risk of LBW infants compared to women with a normal weight (18.5-24.9) and those who were overweight/obese $(\geq 25.0)$. This is consistent with a previous study by Kader and Perera who reported that women with low BMI $<18.5$ had $49 \%$ risk of having LBW infants [18]. A higher risk of LBW was also reported amongst women with a lower BMI $(<18.5)$ in Bangladesh [22]. A plausible reason is that low BMI (underweight) is a marker of marginal tissue nutrient reserves and a predictor of proteinenergy malnutrition leading to fetal under-nutrition, which in turn affects foetal growth [5]. Also, low BMI among HIV 
positive women is induced by reduced dietary intake, malabsorption of nutrients and metabolic alterations within the early stages of infection which affects the foetus' development [23]. However, other studies found a higher risk of LBW among overweight or obese women, although no plausible explanations were provided for their findings [25].

\section{Socio-demographic Factors}

Female infants had a higher risk of LBW compared to males in our study. Overall these results are similar to findings reported in other studies indicating high risk of LBW among female infants compared to their male counterparts [26, 27]. However, other studies reported no statistically significant association between sex of child and LBW [24]. Nevertheless, a popular explanation for the association is that female infants are biologically predisposed to have LBW [25].

Another key finding in our study was that as parity increased (i.e. four or more children), the risk of LBW decreased. These findings are directly in line with other findings that have shown that the more children that a woman has, the lower the risk of LBW with each successive birth [25, 27, 9].Boghossian \& Laughon highlight that birthweight increases with parity (up to 4 or 5 births) but declines thereafter [27].A possible explanation for this varying relationship between parity and birthweight is the priming of a woman's body by the first pregnancy in which the body becomes more efficient with each subsequent pregnancy. However as the woman ages, her reproductive lifespan decreases therefore the body becomes less efficient and is prone to giving birth to a low birthweight infant [27].Nevertheless, in prior cross-sectional studies, these differences between birthweight by parity maybe due to methodological issues such as selection bias[27].

The findings suggested that LBW was not associated with maternal age, maternal education and maternal employment. These findings are inconsistent with findings from other studies that reported that low birthweight is statistically significant with maternal age as well as maternal education and employment $[29,2,18]$.

The association between LBW and wealth quintile, residence type, iron and folate supplement intake, and frequency of antenatal care visits were established by other studies. These findings are inconsistent with findings from this study [29, 18].

Prior studies indicate that there is an association between marital status and LBW [30, 31, 32].Marriage is reported to be an advantageous social tie for the growth of the foetus during the woman's pregnancy due to the support rendered to her by a partner [30]. The current study does not however show a statistically significant relationship between marital status and LBW. This could be explained by selection bias in the data; as expected most pregnant women are of a married status in Zimbabwe [3].

Study Implications

The findings of this study have public health implications transcending. An association between LBW and anaemic women was not confirmed in this study. However, the prevalence of LBW is high among this vulnerable population of HIVpositive women compared to the general population of pregnant women, warranting more attention to their nutritional and health needs given the high risk especially among women who were underweight. Moreover, consideration of HIV status as a risk factor for anaemia and LBW needs to be considered when providing the continuum of care to women for healthier maternal and neonate outcomes [18]. Therefore, nutritional guidelines should be provided as well as relevant nutrient supplements to women during pregnancy to reduce the risk of LBW. Managing high levels of anaemia among HIV infected pregnant women can be done through provision of appropriate nutritious foods. In addition, it is imperative to especially target first time mothers as the first birth was found to be associated with LBW.

Strengths and Limitations of the Study

The study is limited by the cross-sectional design of the study. It is not possible to establish temporality in this study i.e. whether the mothers were HIV-positive during pregnancy or after delivery hence making it challenging to determine which

Page 10/18 
came first the outcome (LBW) or HIV infection. Naturally, the use of secondary data is a limitation as our study relied on the accuracy of written or reported records from the survey, thus, making it difficult to control for the possibility of misclassification bias due to recall bias since factors such birth weight of infants, age, education level and family income were self-reported in the ZDHS. For example, maternal recall was used to report birth weights of infants in the absence of the child's delivery record in the ZDHS [14]. However, the DHS has been collecting data by similar methods for more than two decades, and there has been improvement in the robustness and reliability of datasets [14]. Another apparent limitation of using secondary data is that some important factors were not assessed; the survey did not include vital questions to measure maternal exposure to ART, infant HIV status at birth, obstetric complications during birth, alternative standard anthropometric measures for pregnancy such as pre-pregnancy weight and weight gain during pregnancy, and progression of HIV infection during birth which have been reported as risk factors of LBW in other studies [18, 32, 33]. However, the secondary analysis allowed for completion of the study within the limited academic time frame and came at no cost as no fee was required to obtain access to the DHS dataset. Additionally, the availability and use of a large sample size of a nationally representative dataset was an apparent strength enhancing the power of the study and generalization of the findings to the population of HIV positive women of reproductive age in Zimbabwe.

\section{Conclusions And Recommendations}

The prevalence of anaemia among HIV positive women is high during pregnancy even though maternal anaemia among this group of women in our study was not associated with LBW. Low BMI, female sex and parity are key risk factors of LBW in neonates born to HIV infected women. In Zimbabwe, where the prevalence of HIV is high and rife in an economically challenged era, it is worth noting that policy-makers and clinicians should put in place strategies to encourage frequent ANC visits by HIV pregnant women and develop nutritional guidelines tailored to this group of women. Generally, a key recommendation for practice at policy level is that health care service providers may use findings of this study to develop screening tools that categorize and place the pregnant women into risk -profiles based on certain risk factors; namely from this study by BMI categorization of mother, by expected sex of child and parity. On basis of such categorization, appropriate interventions that address conditions leading to elevated anaemia and LBW among HIV infected pregnant women can be targeted and modified.

Future research using more robust designs such as a prospective study can follow up HIV positive women through pregnancy to establish the association between anaemia and LBW among HIV infected women, whilst controlling for confounding by HIV treatment during the gestation period and earlier and obstetric complications. Furthermore, the association between HIV status of the HIV-exposed infants at birth should further be explored.

In the context of Zimbabwe, the present study has contributed to the understanding of the link between anaemia and LBW among HIV infected pregnant women at population level, factoring in other possible risk factors. No prior research of this magnitude had ever been conducted on a sample of HIV positive women, yet the country is endowed with many population datasets spanning back to many several years. To the best of current knowledge, insufficient systems are currently in place to monitor progress being made towards attaining the UN goal of reducing the prevalence of LBW by $30 \%$ by 2025 [2]. Findings from the study therefore provide a starting point towards amenable factors to modify and allow the country to progress towards the UN target. The research findings also provide cues to health service providers and policy makers on determinants to concentrate new policy guidelines or future research on involving HIV infected women to avert LBW. In general, the health delivery system needs to strengthen awareness on the potentially high risk of LBW common from first births and importance of an adequate nutritional diet during pregnancy to increase BMI to normal levels $\left(18.5 \mathrm{~kg} / \mathrm{m}^{2}-24.9 \mathrm{~kg} / \mathrm{m}^{2}\right)$ including the role of a rich diet to reduce levels of anaemia among HIV women.

\section{Abbreviations}


ANC - Antenatal Care

ART - Anti-retroviral Treatment

DHS-Demographic and Health Survey

HIV- Human Immunodeficiency Virus

LBW - Low Birth Weight

NBW - Normal Birth Weight

PMTCT- Prevention of mother-to-child transmission

RR-Relative Risk

SSA-Sub-Saharan Africa

UNAIDS - Joint United Nations Program in HIV/AIDS

WHO - World Health Organisation

ZDHS-Zimbabwe Demographic and Health Survey

\section{Declarations}

\section{Ethical Approval}

Ethical approval to conduct the study was granted by Monash University Human Research Ethics Committee number: 16716.Permission to use the data was granted by the 2015 ZDHS gatekeepers. Additional approval by the DHS was obtained to access HIV data. In the ZDHS, all individual study participants were made aware that participation in the community health profile was voluntary [15]. In this study, confidentiality and privacy of the subjects was maintained by not disclosing their names or medical history. The dataset was stored on a protected device with a password, only allowing for the authorized researcher's access.

\section{Consent for Publication}

Not applicable

\section{Availability of Data and Materials}

The data that support the findings of this study are available from the Demographic and Health Survey Program (DHS) however restrictions apply to the availability of these data, which were used with the permission from the DHS for this study, and so are not publicly available. Data are however available from the authors upon reasonable request and with the permission of the DHS.

\section{Competing Interests}

The authors declare that they have no competing interests.

\section{Funding}

None 


\section{Author Contributions}

DC conceptualized, analyzed, interpreted the data and wrote the original draft of the manuscript. ST was the major contributor to the supervision of the conceptualization, writing, analysis and interpretation of the study. TJB supervised the writing, analysis and interpretation process. NK and JW contributed to the supervision, conceptualization and the writing of the manuscript.

All authors read, reviewed, edited and approved the final draft of the manuscript.

\section{Acknowledgements}

The authors would like to thank the DHS program for providing access to the data used in the study.

\section{References}

1. Nguyen T Huong. Birth weight and growth during the first two years of life: a study in urban and rural Vietnam Nguyen Thu Huong. BMC Pediatrics. 2014; 13:149

2. World Health Organization. World health assembly global nutrition targets 2025: Low birth weight policy brief. World Health Organization [Internet]. 2012;1-7. Available from: http://www.who.int/nutrition/topics/globaltargets_stunting_policybrief.pdf

3. Feresu SA, Harlow SD, Woelk GB. Risk factors for low birthweight in Zimbabwean women: A secondary data analysis. PLoS ONE. 2015;10:1-17.

4. Rahmati S, Delpishe A, Azami M, Hafezi Ahmadi MR, Sayehmiri K. Maternal Anemia during pregnancy and infant low birth weight: A systematic review and Meta-analysis. International Journal of Reproductive Biomedicine. 2017;15(3):125-34.

5. da Silva Lopes K, Ota E, Shakya P, Dagvadorj A, Balogun OO, Peña-Rosas JP, et al. Effects of nutrition interventions during pregnancy on low birth weight: an overview of systematic reviews. BMJ Global Health. 2017;2(3):e000389.

6. He Z, Bishwajit G, Yaya S, Cheng Z, Zou D. Prevalence of low birth weight and its association with maternal body weight status in selected countries in Africa: a cross-sectional study. BMJ Open.2018 Aug $29 ; 1-8: e 020410$.

7. Zimbabwe National Statistics Agency and ICF International. Zimbabwe Demographic and Health Survey 2015 : Final Report. Rockville, Maryland. 2015.Available from https://dhsprogram.com/pubs/pdf/FR322/FR322.pdf

8. Young MF. Maternal anaemia and risk of mortality: a call for action. Lancet Glob Health. 2018;6(5):e479-ee80.

9. Xiao PL, Zhou YB, Chen Y, Yang MX, Song XX, Shi Y, et al. Association between maternal HIV infection and low birth weight and prematurity: A meta-analysis of cohort studies. BMC Pregnancy and Childbirth. 2015;15(1).

10. K. T, J. M. Anaemia in pregnancy in a setting of high HIV prevalence rates. Southern African Journal of Epidemiology and Infection. 2017;32(4):138-41.

11. Stephen G, Mgongo M, Hussein Hashim T, Katanga J, Stray-Pedersen B, Msuya SE. Anaemia in Pregnancy: Prevalence, Risk Factors, and Adverse Perinatal Outcomes in Northern Tanzania. Anemia. 2018;2018. 
12. Naidoo M, Sartorius B, Tshimanga-tshikala G. Maternal HIV infection and preterm delivery outcomes at an urban district hospital in KwaZulu- Maternal HIV infection and preterm delivery outcomes at an urban district hospital in KwaZulu-Natal 2011. Southern African Journal of Infectious Diseases. 2016;31(1):25-8.

13. Evans C, Humphrey JH, Ntozini R, Prendergast AJ. HIV-exposed uninfected infants in Zimbabwe: Insights into health outcomes in the pre-antiretroviral therapy era. Frontiers in Immunology. 2016;7(JUN):1-12.

14. Zimbabwe National Statistics Agency. Facts and Figures 2016. Zimbabwe Demographic and Health Survey. 2016. Available from http://www.zimstat.co.zw/sites/default/files/img/publications/Facts\%20and\%20Figures/Fact_Figures\%20_2016.pdf

15. Hirakata VN. Bias of using odds ratio estimates in multinomial logistic regressions to estimate relative risk or prevalence ratio and alternatives Viés da razão de chances estimada pela regressão logística multinomial para estimar o risco relativo ou a razão de preval. 2014;30(1):21-9.

16. Nandlal V, Moodley D, Grobler A, Bagratee J, Maharaj NR, Richardson P. Anaemia in Pregnancy Is Associated with Advanced HIV Disease. 2014;9(9).

17. Msamila S, M. The Association between Maternal HIV Status and Low Birth Weight Offspring , Malawi DHS 2010. 2018.Available from https://www.semanticscholar.org/paper/The-Association-between-Maternal-HIV-Status-andLow-Msamila/c1bc75991994e25714b97b0e5566d9fb154f6140

18. Kader M, Perera NKP. Socio-economic and nutritional determinants of low birth weight in India. North American Journal of Medical Sciences. 2014;6(7):302-8.

19. Fowkes FJI, Moore KA, Opi DH, Simpson JA, Langham F, Stanisic DI, et al. Iron deficiency during pregnancy is associated with a reduced risk of adverse birth outcomes in a malaria-endemic area in a longitudinal cohort study. BMC Medicine. 2018;16(1):1-10.

20. Haider BA, Olofin I, Wang M, Spiegelman D, Ezzati M, Fawzi WW. Anaemia, prenatal iron use, and risk of adverse pregnancy outcomes: systematic review and meta-analysis. BMJ (Clinical research ed). 2013;346(June):f3443.

21. Islam M, Khan M. Incidence of and Risk Factors for Small Size Babies in Bangladesh. International Journal of Community \& Family Medicine. 2016;1(2):1-7.

22. de Pee S, Semba RD. Role of nutrition in HIV infection: Review of evidence for more effective programming in resource-limited settings. Food and Nutrition Bulletin. 2010;31(4):313-44.

23. McDonald SD, Han Z, Mulla S, Beyene J. Overweight and obesity in mothers and risk of preterm birth and low birth weight infants: Systematic review and meta-analyses. BMJ (Online). 2010;341(7765):187.

24. Asmare G, Berhan N, Berhanu M, Alebel A. Determinants of low birth weight among neonates born in Amhara Regional State Referral Hospitals of Ethiopia: Unmatched case control study. BMC Research Notes. 2018;11(1):1-7.

25. Bugssa G, Dimtsu B, Alemayehu M. Socio Demographic and Maternal Determinants of Low Birth Weight at Mekelle Hospital , Northern Ethiopia: A Cross Sectional Study. American Journal of Advanced Drug Delivery. 2014;2(5):609-18.

26. Mahumud RA, Sultana M, Sarker AR. Distribution and Determinants of Low Birth Weight in Developing Countries. J Prev Med Public Health. 2017;50(1):18-28. 
27. Boghossian NS, Laughon SK. Consecutive Pregnancy Cohort. Paediatric and Perinatal Epidemiology. 2015;28(2):106-15.

28. Darnton-hill I, Mkparu UC. Micronutrients in Pregnancy in Low- and Middle-Income Countries. 2015;1744-68.

29. Fosu MO, Abdul-rahaman I, Yekeen R. Maternal Risk Factors for Low Birth Weight in a District Hospital in Ashanti Region of Ghana. 2013;2(4):48-54.

30. Muula AS, Siziya S, Rudatsikira E. Parity and Maternal education are associated with low birth weight in Malawi. Afr Health Sci. 2011;11(1):65-71.

31. Mohd Zain N, Low W.Y, Othman S. Impact of Maternal Marital Status on Birth Outcomes Among Young Malaysian Women: A Prospective Cohort Study. Asia Pacific Journal of Public Health. 2015; 27(3):335-347.

32. Sharma M, Mishra S. Effects of Maternal Health and Nutrition on Birth Weight of Infant. International Journal of Science and Research. 2014;3(6):855-8.

33. Sulaiman S, Othman S, Razali N, Hassan J. Obstetric and perinatal outcome in teenage pregnancies. South African Journal of Obstetrics and Gynaecology. 2013;19(3):77.

\section{Figures}




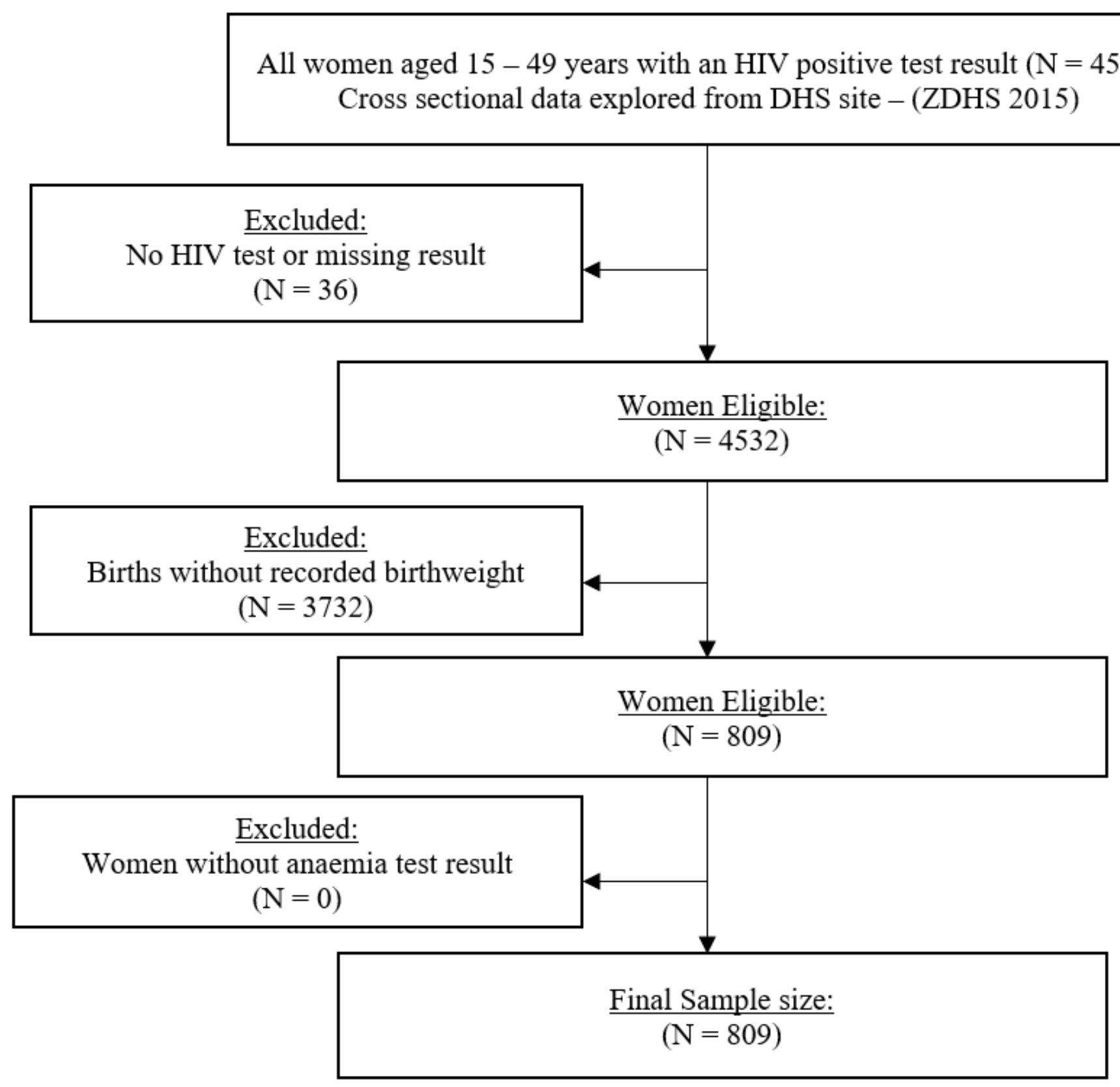

Figure 1

Flow chart of selection of study participants 


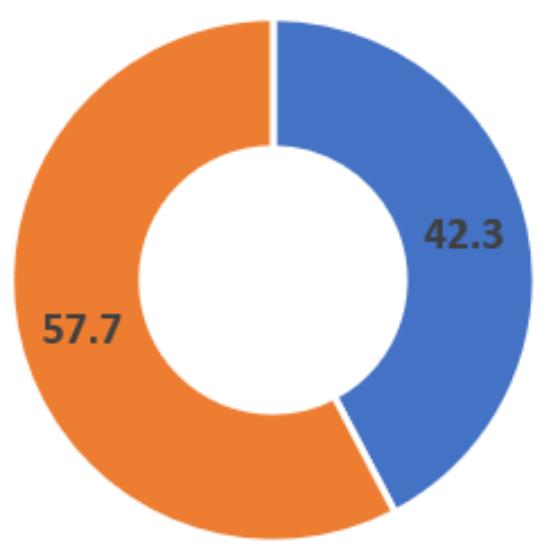

- Anaemic (\%) Non-anaemic (\%)

\section{Figure 2}

Prevalence of maternal anaemia (\%) among HIV infected pregnant women in Zimbabwe, 2015

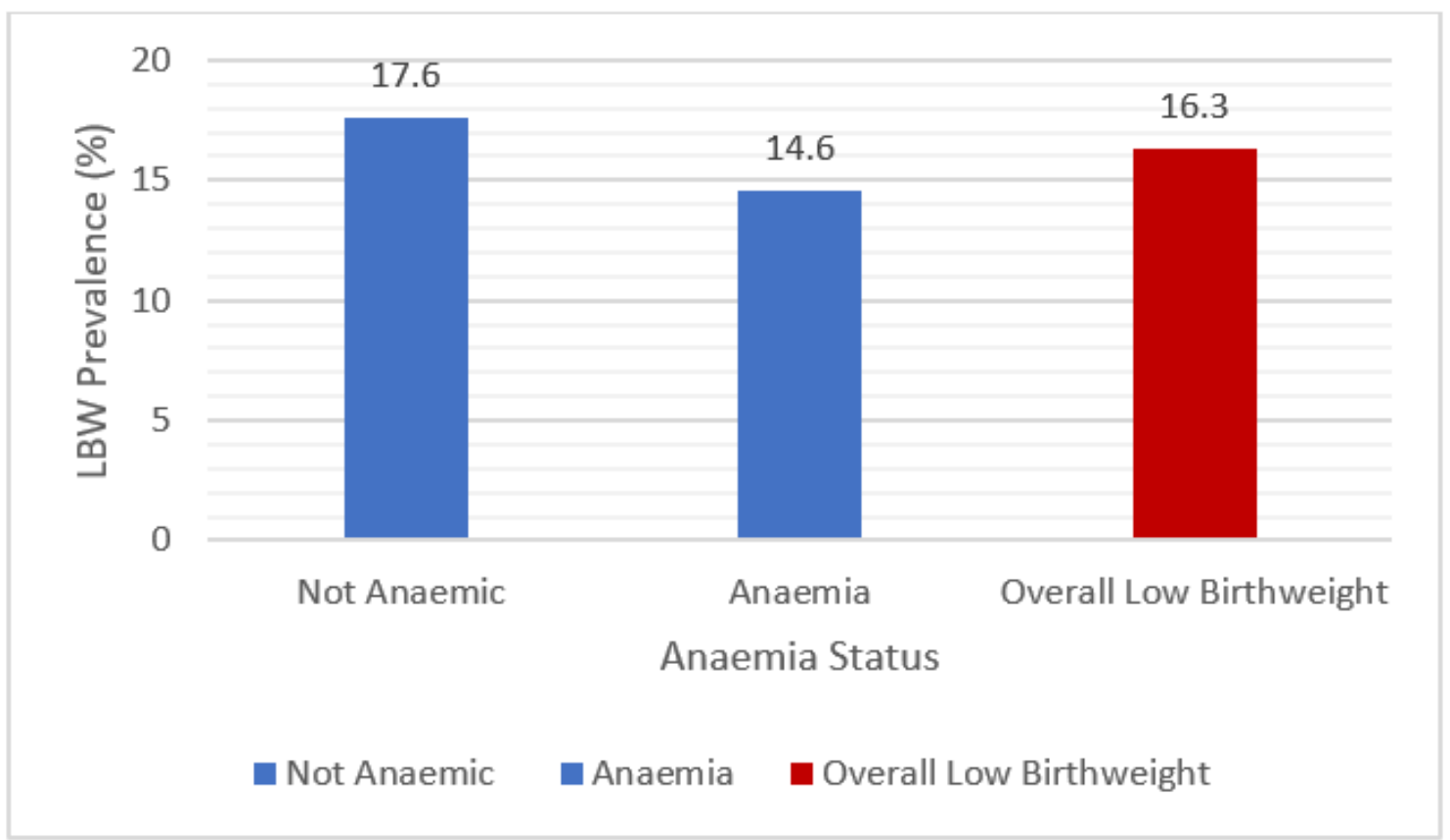

$*$ p-value $=0.264$

Figure 3

Prevalence of low birth weight (\%) by maternal anaemia status in Zimbabwe, 2015 


\section{Figure 4 not included with this version.}

Figure 4

Not included with this version of the manuscript.

Figure 5 not included with this version.

Figure 5

Not included with this version of the manuscript. 